\title{
Drama Scenes in Higher Education: A Method to Stimulate Students' Interest, Encourage Involvement and Develop Reflective Understanding
}

\author{
Ahmad M. Tawalbeh, Hesham El Marsafawy, Rumpa Roy \\ Gulf University, Bahrain
}

\begin{abstract}
Drama takes various forms which reflect cultural values, past happenings, future trends, socio cultural and behavioral aspect. In return the various forms of drama have impact on entertainment as well as delivering instructive messages. Utilizing drama scenes/videos in classroom not only facilitates learning process in higher education but helps in retrieving information, stimulating students' interest, encouraging student engagement, and developing reflective understanding. This proves to be an effective teaching -learning method provided the chosen scenes are well aligned with the topics and reflect learning outcome. The research aims to measure the impact of utilizing drama in classroom learning in higher education and to develop a framework for implementing this tool effectively in classroom. Staff and students at Gulf University, Bahrain who responded to the surveys confirmed that this method has impact on student learning environment and achievement of learning outcomes. This innovative method is able to stimulate student interest in the courses' topics, enhance student engagement in class and develop reflective understanding.
\end{abstract}

Keywords: Academic Programs; Experimental methodology; Teaching and learning; Instructive messages; Learning environment 


\section{Introduction}

Drama is perceived as an art of representing story in performance where one or more characters are involved in series of events, situations and occasions. The characters involved in the drama interact thorough dialogues and/or actions where emotions, believes, wishes, possibilities etc. are represented within harmonic and/or conflicting contexts. Drama performance/play is mostly associated with other arts such as music, songs, lighting effects, existing and created locations and settings with special features as well as costumes and makeup that match with timeframe and context of the story (Longley, 2018). Drama could take several forms such as audio represented drama where the listener can imagine the visual impression of the characters and physical context. The other form is the visual drama such as theatre drama with live performance, cinema and TV play. The various forms of drama could have wide range of aims such as entertaining, telling histories, predicting future, delivering instructive messages, representing cultures, reflecting social, political and economic issues as well as expressing emotions, psychological and behavioral aspects (Albalawi, 2014).

Within this context, using drama in teaching and learning develops personality and emotional intelligence skill of the students (Işyar, 2017). There is a shift in $21^{\text {st }}$ century education from passive lecture-based teaching to active learning where each student responds uniquely in different teaching learning situations. Visual arts can lead to significant outcome while integrating across the curriculum of humanities, arts, design etc. (Punzalan, 2018). Creative drama leads to students' achievements in Information Technology courses apart from developing social and language skill (Özek,2016). Creative drama can be adapted as instructional strategy to develop students' learning on sustainable living and production Özgül (2015). Amidst cultural globalization television drama has transformed the lifestyle and values of people leading towards commercialization and westernization (Mustaffa \& Salleh, 2014).

\subsection{Drama Scenes in Higher Education}

Utilization of drama not only facilitates learning process in any discipline but helps in retrieval of events and facts, stimulates creative interest of the students, promotes social relation between the students themselves and between student and instructors (Moore, 2004). At several schools and higher education institutions performing drama by students and instructors has been used as strategy of teaching and learning (Işyar, 2017). However, existing research has not explored much about presenting drama scenes to students which have direct or indirect relation with the topic or subject that should be delivered to the students. Utilizing drama scenes in teaching and learning processes shall ensure better engagement of students in creative learning environment. Much depends on how well the scene is selected and linked to the topic and subject within the intended learning outcome/s reflecting deeper understanding of the subject. Applied Drama, by its nature, is capable of impacting lives, both at individual, group and community level. It can bring transformation in the lives of people impacting social and psychological wellbeing (Moyo, 2015). It is the responsibility of the instructor/facilitator to foster reflection of movies in concepts and principles with attitudinal change (Gonzalez et al., 2015). Research shows the impact of drama as a teaching and learning tool in understanding Business modules and context leading to enhancement in reflective writing, assessment outcome (Kalidas, 2013). There is statistically significant difference between the experience of 
experimental group and control group through tolerance test while measuring creativity using drama in learning foreign language (Albalawi, 2014).

The study aims to develop a framework for effective utilization of visual drama as teaching and learning method in higher education and its implementation in the best possible manner. Such creative method shall have positive impact on the student engagement, reflective understanding and achievement in a stimulating environment. Focus is given to identify relevant drama scenes well aligned with the topic or context instilling the imagination of the students. The study explores the experimental way to introduce range of drama scenes presented to the students in various academic programs and its impact on the reflective understanding and skills.

\section{Methods}

This research is descriptive in nature. Primary data is collected through conducting survey and accordingly questionnaire is designed. The researchers adapted experimental methodology in which classes from different academic programs at Gulf University, Bahrain have been selected in which course instructors displayed drama scene/video to students. A survey was conducted to know the awareness of the Gulf University academic staff in utilizing drama scenes and its impact on student engagement and reflective understanding. Seventeen academic staff have completed the survey and the responses have been analyzed. The profile of the staff shows that $29 \%$ of the respondents were from Business and Management, followed by $23 \%$ of the staff from Accounting and Finance specialization, 12\% from Engineering, another 14\% from Art \& Design and the remaining 22\% from Media and Public Relation specialization. Majority of the staff possess more than 10 years of teaching experience who participated in more than 3 training sessions in innovative teaching-learning method.

Another survey to measure the impact of drama scenes in class was conducted with the students who experienced the innovative method in the class. Forty-two responses were collected within a span of 3 days by visiting classes. Prior to visiting classes, the researchers coordinated with the academic staff who volunteered to present video/drama scene/movie clip in the class.

The demographic profile of the students shows that half of the students were male and remaining are females. Majority (64\%) of the students belong to age group 25-35 years, followed by $24 \%$ students in the age group 17-25 years. Out of the 42 respondents $64 \%$ were Bahraini nationals, remaining were expatriates and international students. Students across the academic programs participated in the survey. For example, $67 \%$ of the students were from Bachelor of Mass Communication Program, $14 \%$ of the students from Bachelor of Human Resource Management Program, 10\% of the students from Bachelor of Accounting program and the remaining students from Bachelor of Interior Design Engineering program.

Results of both the surveys have been analyzed in excel to derive charts and average and interpreted to measure the impact of such innovative method in teaching-learning and student experience in higher education. Based on the analysis a framework has been suggested for effective utilization of drama scenes in higher education teaching and learning. 


\section{International Conference on New}

\section{Approaches in EDUCATION}
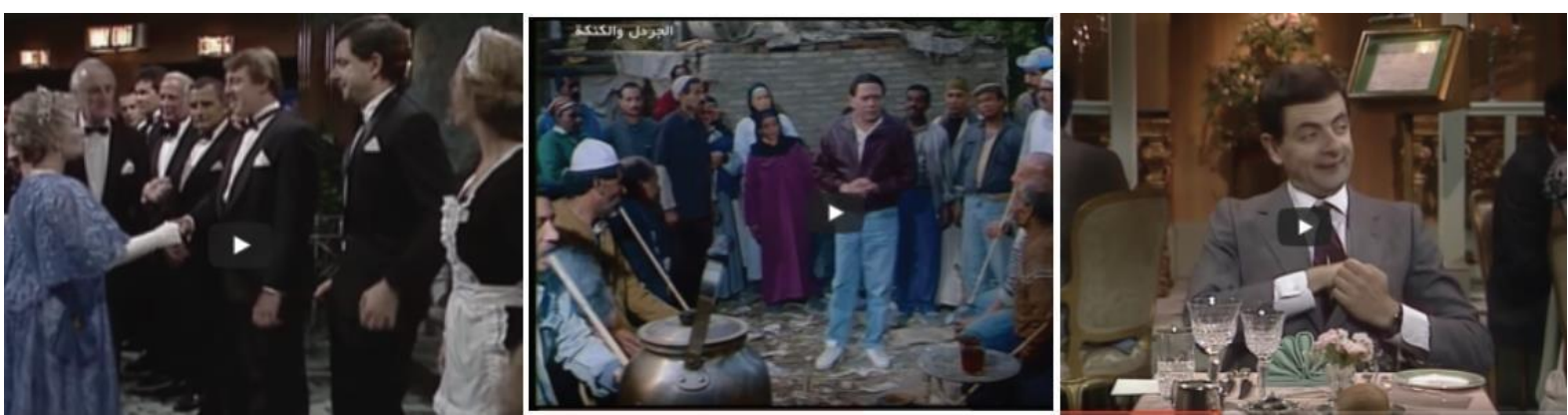

Figure 1: Samples of Drama Scenes utilized by Academic Staff in the Classes

\section{Results}

The researchers analyzed the conducted surveys with academic staff and students from different academic programs at Gulf University. The following sections provide insights into the impact of utilizing drama scenes in sample cases.

\subsection{Instructors' Responses}

The results of the staff survey is represented by using graphs, charts and average score. Regarding the awareness of GU staff about the method of using drama scenes in classroom teaching and learning, 53\% of the staff expressed that they are aware of this innovative method and they noted that they are previously utilizing the method in their classes.

The researchers aimed to explore the perception of the staff in using drama scenes in class. Majority (54\%) of the staff opined that presenting drama scenes from movies related to the topics of the lecture in the classroom is most appropriate tool. Forty percent of the staff mentioned that presenting video clips related to the topic is a useful tool.

The result further shows that majority $(76 \%)$ of the respondents use drama scenes from international films/videos in the class. $53 \%$ of the staff use relevant drama/movie scenes during the middle of the lecture, followed by $35 \%$ who present the video/scene at the beginning of the lecture. Majority (65\%) of the staff opined that chosen drama scenes/video are aligned with course intended learning outcomes; $24 \%$ of the staff choose the drama scenes for entertaining purposes as well.

Figure 2 illustrates the assessment methods used by the course instructors to measure the impact of using drama scenes in higher education teaching-learning. 


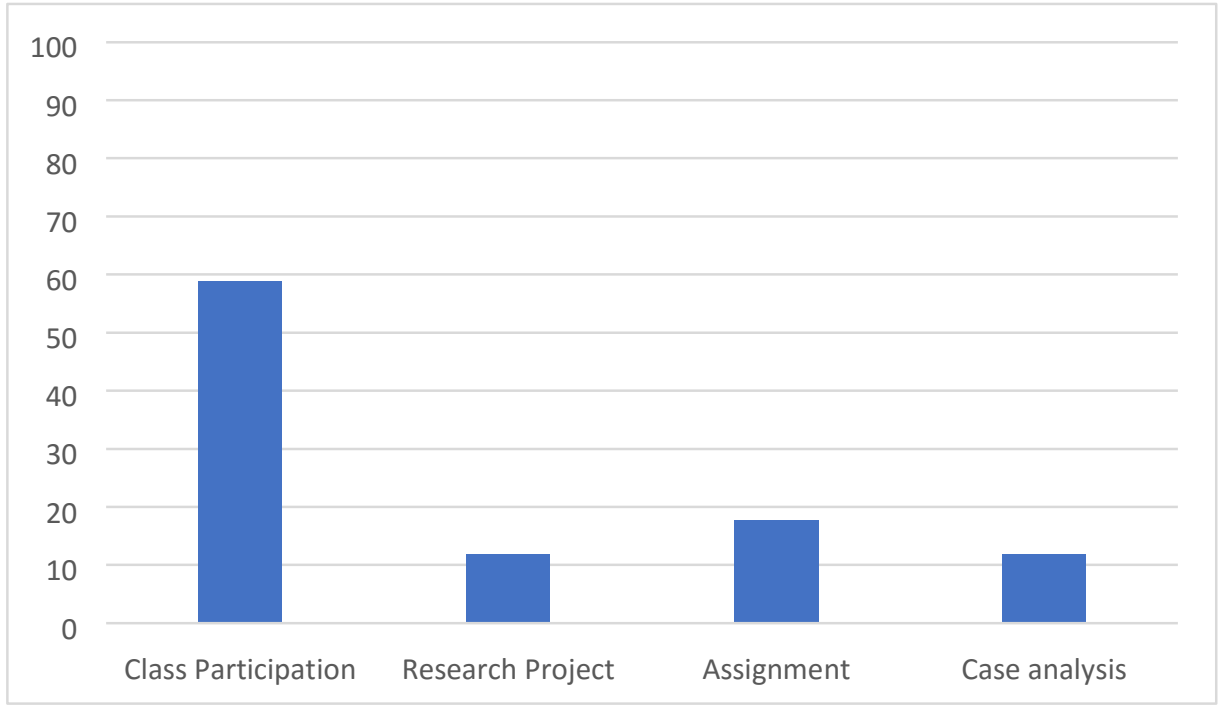

Figure 2: Assessment Methods Measuring Impact of Drama Scenes

Figure 2 shows that $58.8 \%$ of the course instructors measure the impact of this innovative method through class participation, followed by $17.6 \%$ who measure through research project, $11.8 \%$ through assignment and the remaining $11.8 \%$ depend on case study.

Figure 3 illustrates the impact of using drama scenes on students as perceived by the course instructors, where 1 is very low impact and 5 is very high impact.

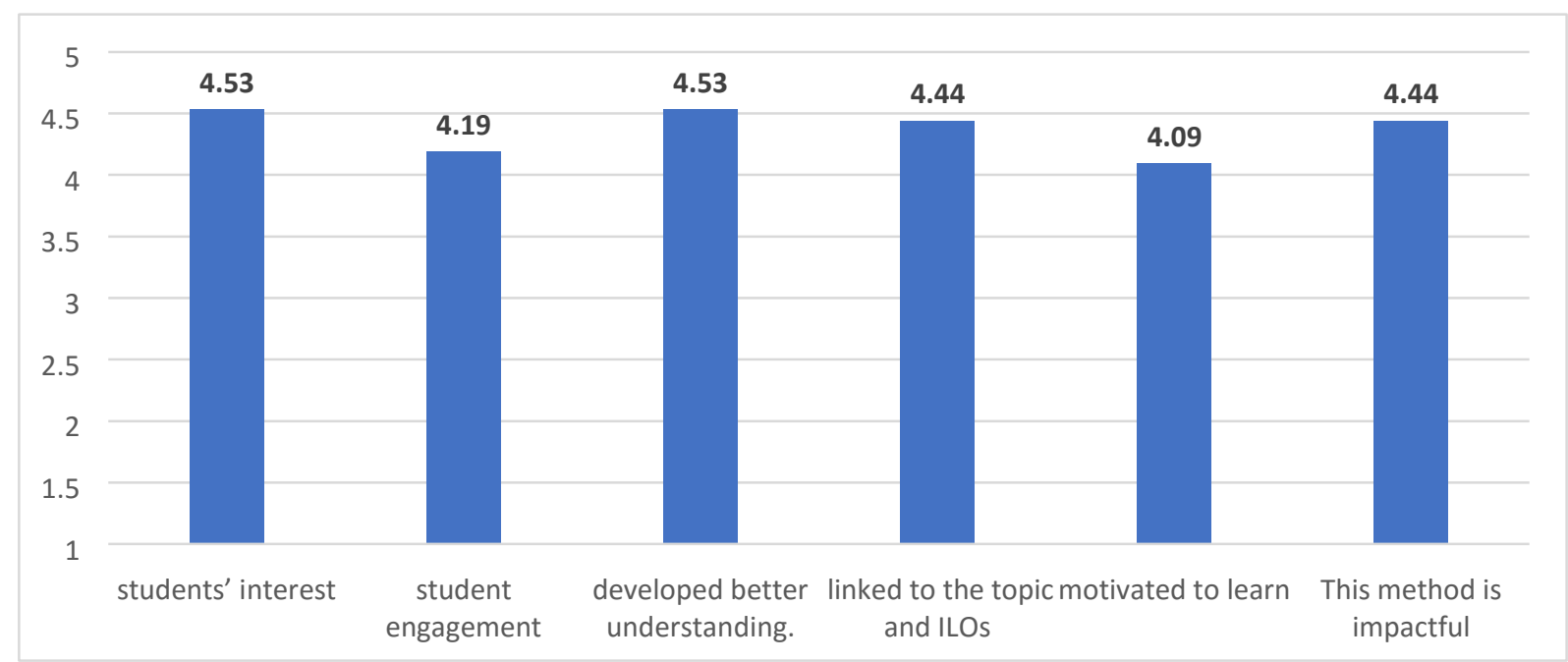

Figure 3: Average Responses of Instructors Feedback on Impact of Using Drama Scenes on Students

The above figure shows that for each of the parameter the average response is ranging from 4.53 to 4.09 on a scale 1 to 5 . This implies the high impact of this method on student learning experience as perceived by the staff. More specifically majority of the staff agreed that this method has increased students' interest, engagement, and understanding of the concepts. The high average response for the parameters confirms that staff believes that this method has motivated the students to learn and this method is impactful on student learning experience. 


\subsection{Students' Responses}

The students attended the sessions where drama scenes/videos were presented. Accordingly the students participated in the survey. The following sections summarize the analysis of the student survey.

\subsubsection{Impact of Using Drama Scenes on Classroom Learning Environment}

In the first section of the survey students provided feedback or their level of agreement or disagreement on a five-point Likert scale (1- strongly agree, 2- agree, 3- neutral, 4- disagree, 5strongly disagree) for given statements about the method of using drama scenes in the class. The average score for the statements is summarized below in Figure 4:

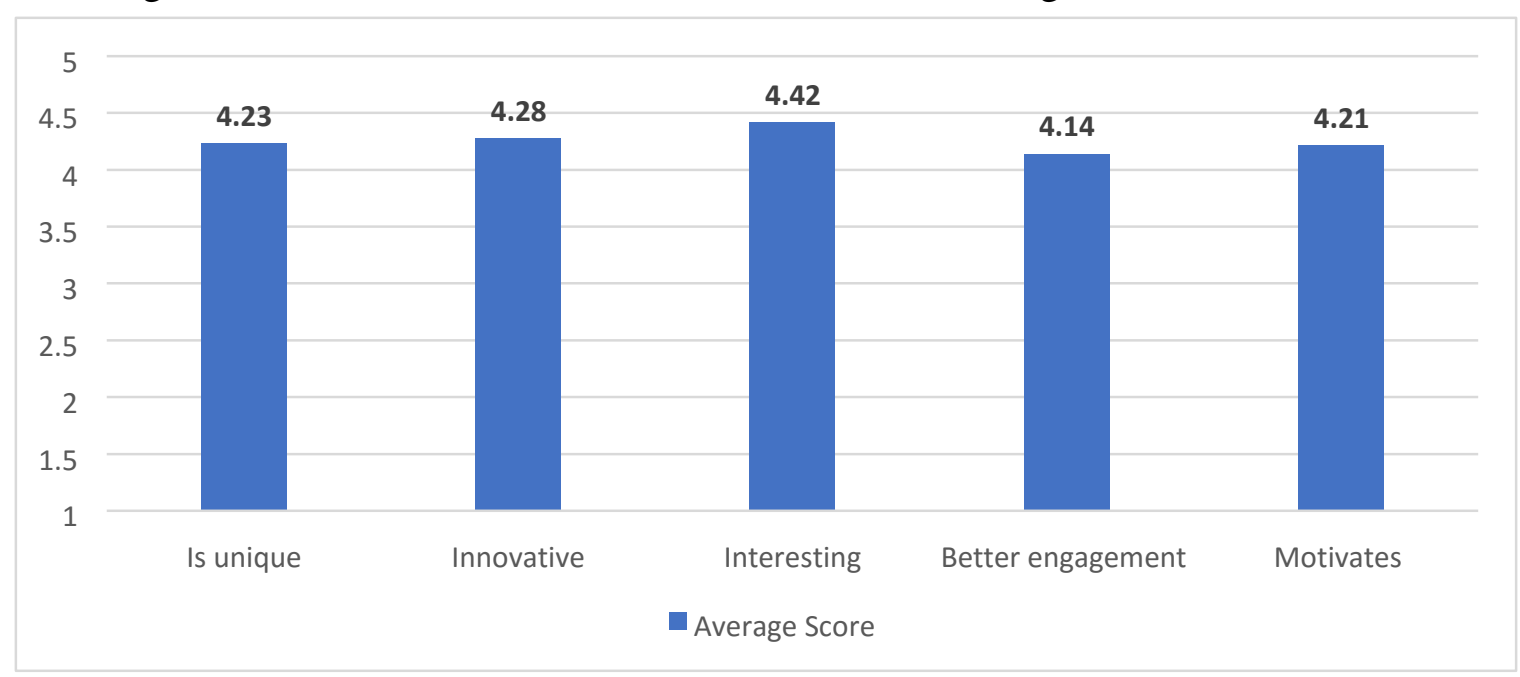

Figure 4: Students' Average Response on Impact of Using Drama in Classroom

Figure 4 depicts that students agreed completely with all statements (average score ranging between 4.42 and 4.14 on a scale 1 to 5) related to the innovative teaching- learning method in classroom. The cumulative average of 4.26 of all the above parameters show the satisfaction of the students about using drama scenes in class. Students appreciated this unique and innovative method and believed that class became enjoyable and interesting. Students acknowledged that it led to better class engagement and motivated them to learn more about the topic covered in the class.

\subsubsection{Impact of Using Drama Scenes on the Achievement of Learning Outcomes:}

Students were asked to show their level of agreement on different aspects to measure the impact of this method on achievement of learning outcome which is depicted in figure 5. 


\section{International Conference on New}

\section{Approaches in EDUCATION}

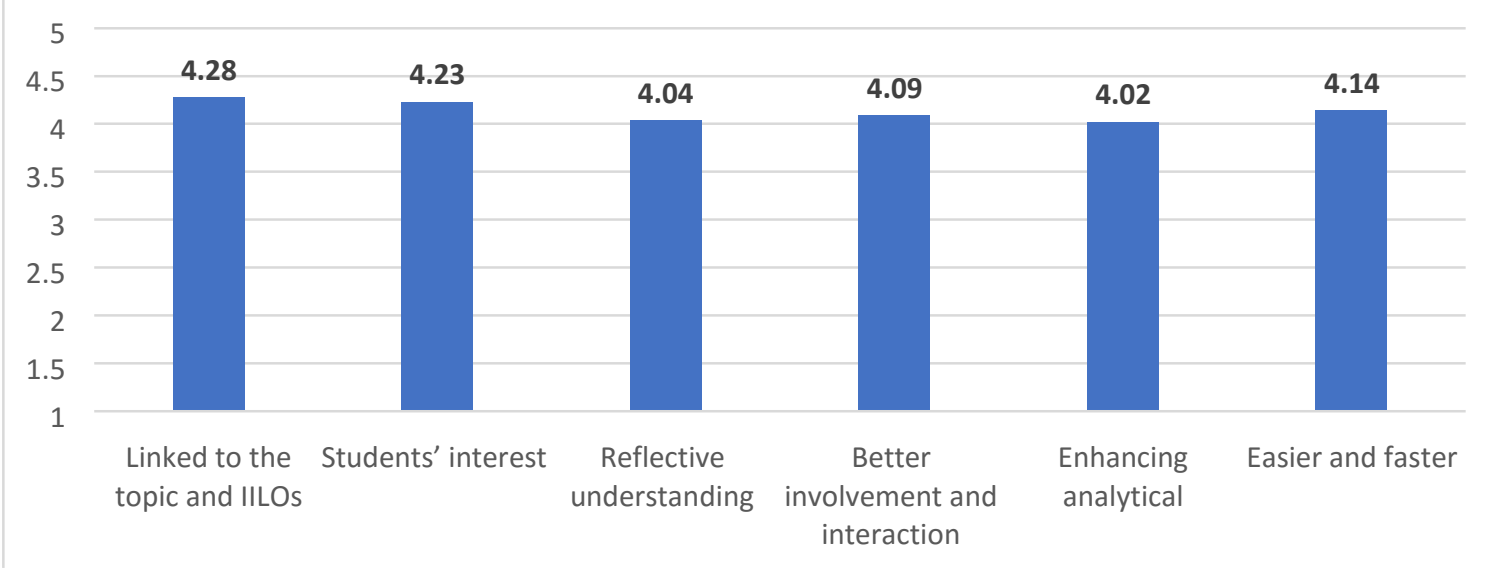

Figure 5: Students' Average Response on Impact of Using Drama Scenes on Achievement of Learning Outcomes

Figure 5 depicts that students agreed with all statements related to impact of this innovative method on learning outcomes (average responses ranging between 4.28 and 4.02) related to the innovative teaching- learning method in classroom. The combined average of 4.13 of all the above parameters show the students' overall perception/satisfaction about using drama scenes in class. Students acknowledged that drama scenes presented in the class were well linked to the topic and intended learning outcome. Students agreed that this method could stimulate student interest in the topic and the course. They further accepted that this method developed reflective understanding of the concepts and theories. They appreciated the impact of this method on class interaction and communication between themselves and with instructors. Students agreed that this method enhanced their analytical and critical thinking skills. This facilitated their learning and the average response of 4.13 indicates overall high impact of the method on achieving the learning outcome as perceived by the students.

The survey result further shows that $63 \%$ of the students suggested using similar method to practice in other courses, $27 \%$ of the students agreed to some extent, only $10 \%$ of the respondents did not show interest to apply this method for other courses.

\section{Discussion}

Course instructors opined that this method has increased students' interest, engagement in the class, developed better understanding of the taught theories and concepts. According to them, drama scene/video chosen to present in the class is well linked to topic and intended learning outcome. The staff observed the positive impact of this method on teaching-learning and student experience. Student survey results lead to similar inferences and there is clear judgement and perception of the students regarding the impact of using drama scenes on classroom learning environment and on the achievement of learning outcome. According to the students, the method is unique, innovative and enjoyable. This provides better insight to the topic and ensures better participation in class resulting in active learning environment. Students have appreciated the impact of using this method on course learning outcome since the video/movie clip/drama scene is well aligned with the topic and has enhanced critical thinking 
and analytical skill of the students. This method not only stimulates students' interest but also develops reflective understanding. Hence, it can be interpreted that both staff and students have acknowledged the high impact of this method on learning environment and achievement of learning outcome.

\section{Framework for Effective Utilization of Drama Scenes in Higher Education}

Based on the study results, the researchers developed a framework for effective utilization of drama scenes in higher education.

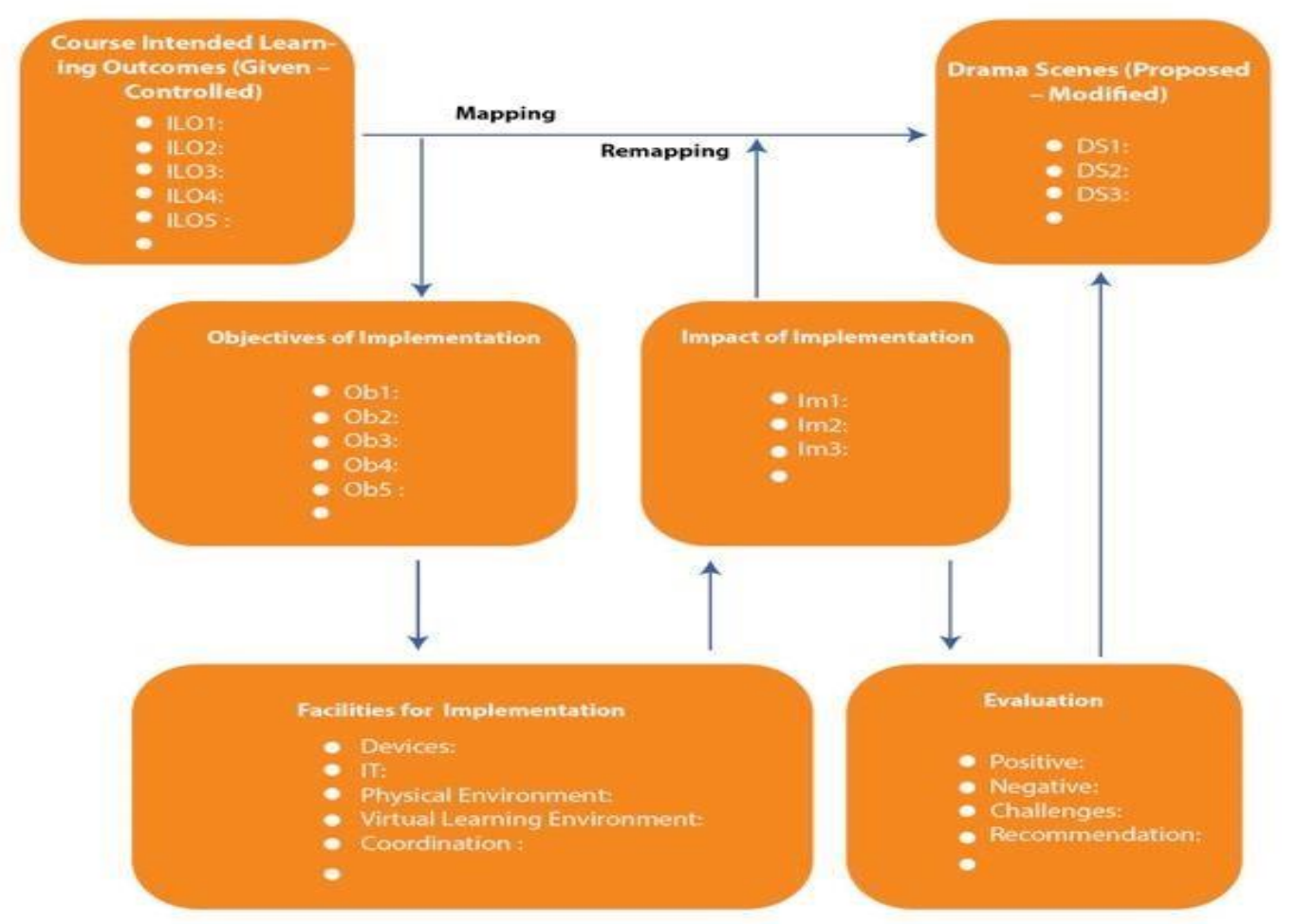

Figure 6: Framework for Effective Utilization of Drama Scenes in Higher Education

As illustrated in Figure 6 proposed drama scenes shall be mapped to course intended learning outcome. The course instructor shall identify the objectives of implementing this method in the context of the particular course. In coordination with support services, facilities for implementation shall be provided. The impact of using this innovative method shall be identified by the instructor. To close the loop the course instructor shall evaluate/review the learning experience of the students and shall identify the positive aspects and challenges of such implementation in classroom. The impact and the evaluation shall result in remapping of drama scenes to course learning outcomes as well as reselecting drama scenes. This framework underpins the principle of continuous quality enhancement. 


\section{Conclusion}

Drama has been utilized for educational purposes over the years. Particularly at schools and higher education institutions performing drama by students and instructors has been identified as teaching and learning strategy. Such teaching and learning practices have been culminated into scholarly work and research projects. However, this research explores the utilization of drama scenes to university students which have direct relation with the topic or subject that is delivered in the class across the academic programs. Experimental methodology provided opportunity to receive the feedback of the students who participated in the class where the academic staff presented movie/ drama scenes related to topic. Both staff and students appreciated the positive impact of this method on learning environment and achievement of learning outcome and suggested that this method shall be applied in other courses across the academic programs. The researchers have developed a framework for effective utilization of drama scenes in higher education teaching and learning. The course instructor shall align the selected drama scenes with intended learning outcomes. Objectives and impact of implementing this method shall be identified along with the facilities and services. Once implemented the instructor shall evaluate the experience and the impact on student learning environment and achievement of learning outcomes. This in return shall be reflected in remapping and reselection of drama scenes in the next cycle of implementation.

\section{Acknowledgement}

The idea of this research paper stems from gulf university's endeavor to explore innovative teaching and learning approaches in higher education and team research. The team is highly indebted to the staff and students who participated in the surveys and provided valuable feedback. The team also acknowledges the support volunteered by colleague to generate results of the survey in quantitative form. Finally, the researchers would like to express heartfelt thanks to University Management in supporting the research. 


\section{References}

[1] Albalawi, B. (2014). 'Effectiveness of Teaching English Subject using Drama on the Development of Students' Creative Thinking', IOSR Journal of Research \& Method in Education (IOSR-JRME) e-ISSN: 2320-7388, p-ISSN: 2320-737X Volume 4, Issue 6 Ver. I (Nov - Dec. 2014), PP 54-63 www.iosrjournals.org

[2] Gonzalez, B.P., Graziela, M. (2015). 'Education through Movies: Improving teaching skills and fostering reflection among students and teachers,' Journal Issue: Journal for Learning through the Arts

[3] İşyar, O. (2017). 'The Use of "Drama in Education" in Primary Schools from the Viewpoint of the Classroom Teachers: A Mixed Method Research,' Journal of Education and Practice, Vol.8, No.28, 2017

[4] Kalidas, C. (2013). "Drama: A Tool for Learning”, Procedia - Social and Behavioral Sciences 123 (2014) 444 - 449, Available online at www.sciencedirect.com

[5] Longley, R. (2019). What Is Drama? Literary Definition and Examples. Retrieved June/July, 2019, from https://www.thoughtco.com/drama-literary-definition-4171972

[6] Moore, M. (2004). 'Using Drama as an Effective Method to Teach Elementary Students', Senior Honors Theses. 113. http://commons.emich.edu/honors/113

[7] Moyo, C. (2015). 'Applied Drama and the Higher Education Learning Spaces: A Reflective Analysis', Journal of Education and Practice, Vol.6, No.6, 2015

[8] Mustaffa, C. and Salleh, I. (2014). 'Impact of Television Drama from Audience Reception Perspective', Procedia - Social and Behavioral Sciences 155 (2014) 203 - 208, Available online at www.sciencedirect.com

[9] Punzalan, Jovita. F. (2018). 'The Impact of Visual Arts in Students' Academic Performance', International Journal of Education and Research, Vol. 6 No. 7 July 2018 [10] Özek, M. (2016). 'The Effect of Creative Drama on Student Achievement in The Course of Information Technologies', Journal of Education and Training Studies Vol. 4, No. 6; June 2016

[11] Özgül, K. (2015). 'Creative Drama in the Teaching of Education for Sustainable Development: Sample Activity about Sustainability and Sustainable Production', Journal of Environmental Sustainability: Vol. 4: Iss. 4, Article 4. Available at: http://scholarworks.rit.edu/jes/vol4/iss4/4 